\title{
Improving Mechanical Properties of cp Titanium by Heat Treatment Optimization
}

\author{
Francis Wagner,* Abdelouahab Ouarem, Thiebaud Richeton, and Laszlo S. Toth
}

The yield stress and the ductility are very important mechanical quantities for materials selection. The paper deals with the question: how far is it possible to increase the yield stress without a significant loss of ductility by optimizing the final heat treatment in the elaboration stage. Commercially pure titanium sheets are subjected to different thermo-mechanical treatments to produce seven metallurgical states. The textures and the microstructures of the samples are studied by Electron Back Scattering Diffraction measurements, the mechanical behavior by tensile testing along the previous rolling, and the transverse directions of the sheet. The obtained microstructures display different grain sizes and varying fractions of recrystallized grains, together with slightly dissimilar textures. The yield stress increases with the decreasing grain size and obeys the classical Hall-Petch law. The grain size reduction results in a small decrease of ductility for extension along the rolling direction when the recrystallized volume fraction is higher than $80 \%$. For extension along the transverse direction, however, the homogeneous deformation strongly decreases as soon as the material contains a small fraction of non-recrystallized grains. A good compromise between high yield stress and ductility is identified in a metallurgical state close to the end of primary recrystallization. This material state insures a relatively small grain size with all grains being in a recrystallized state.

\section{Introduction}

When selecting materials for structures, the condition $\sigma_{\max }<\sigma_{e}$ is often imposed, where $\sigma_{\max }$ is the maximal loading stress and $\sigma_{e}$ is the yield stress (YS). A higher value of the yield stress frequently allows a slimmer and lighter component to be employed. This principle is classically illustrated in the material selection charts proposed by Ashby. ${ }^{[1]}$ On the other hand, when metal parts need to be formed into a given shape, ductility requirements become important. The material selection in this case is often a compromise between high $\sigma_{e}$ and good ductility.

Dr. F. Wagner, Dr. A. Ouarem, Dr. T. Richeton,

Dr. L. S. Toth

Labex DAMAS, Université de Loraine, France

E-mail: francis.wagner@univ-lorraine.fr

Dr. F. Wagner, Dr. T. Richeton, Dr. L. S. Toth

LEM3 (UMR 7239) CNRS/Université de Lorraine,

Metz, France
Such a compromise requires one to optimize the material processing, especially during the last stages of plastic deformation and final heat treatment. The standard heat treatments lead usually to recrystallization and grain growth in view of recovering some ductility and homogenizing the material. In few cases, in order to keep a high yield stress, the recrystallization is only partial giving rise to a more heterogeneous microstructure with a mixture of recrystallized and not recrystallyzed grains (one can view the not recrystallized part as a "supplementary phase"). This is, for example, the case in the elaboration of TA3V2.5 tubes. ${ }^{[2,3]}$

The present paper deals with the optimization of heat treatments in the case of commercially pure (cp) titanium sheets. It analyzes the consequences for the mechanical properties of several heat treatments leading to different metallurgical states (recrystallization + grain growth, end of primary recrystallization, partial recrystallization). For partial recrystallization, only cases with at least $60 \%$ of the grains recrystallized were considered. The present study intends to determine how far the YS can be increased without a significant loss of ductility by adjusting the heat treatments after a given cold plastic deformation. Cp titanium seems indeed well suited for such a study. It is a mono-phased alloy which makes easier the interpretation of the relationships between microstructural parameters and mechanical properties. Moreover, titanium alloys are known to be very sensitive to texture ${ }^{[4-7]}$ and to microstructure parameters as grain size, for example. ${ }^{[6,8]}$

\section{Materials and Methods}

The as-received material was a $2 \mathrm{~mm}$ thick plate of commercially pure titanium (Ti grade 2 according to TIMET) obtained in the last stage by cold rolling followed by a heat treatment. It was in a fully recrystallized state with a mean grain size of about $10 \mu \mathrm{m}$. Table 1 gives the chemical composition of this alloy.

In order to generate several microstructural states, various deformation and heat treatment conditions were applied, see Table 2. Seven specimens were then used for further investigations. The specimens denoted $R j$ (with $j=1,2,3$, 
Table 1. Chemical composition (\% in weight) of the alloy used in this study

\begin{tabular}{cccccc}
$\mathrm{C}$ & $\mathrm{Fe}$ & $\mathrm{N}$ & $\mathrm{O}$ & $\mathrm{H}$ & $\mathrm{Ti}$ \\
\hline $0.006-0.011$ & $0.123-0.128$ & $0.002-0.004$ & $0.101-0.108$ & $0.0034-0.0042$ & Balance
\end{tabular}

or 4) were cold rolled up to $75 \%$ reduction parallel to the previous rolling direction $(R D)$ (the one used to produce the as received material), whereas the specimens denoted $\mathrm{Tj}$ (with $j=1,2$, or 3 ) were cold rolled also up to $75 \%$, but parallel to the previous transverse direction (TD). This second specimen set (T-type) was made in order to generate a texture different from the one obtained for the $R$-type. Cold rolling was achieved with a laboratory rolling mill by multi-passes. Heat treatments were performed in a laboratory furnace with secondary vacuum under isothermal conditions. Specimens were water quenched at the end of the annealing. Although it exists several studies on the evolution of microstructure and texture for titanium alloys, from the experimental point of view, ${ }^{[4,8]}$ as well as from the modeling one, ${ }^{[9]}$ none is enough precise to set the annealing conditions to reach exactly a given microstructural state. Annealing was then conducted in a more empirical way with several trials until the wished microstructures were obtained. Before the mechanical tests, the microstructures were studied by using EBSD maps. EBSD maps were obtained using a Zeiss Supra 40 FEG-SEM and a Bruker Quantax EBSD system. Grains were detected with a maximal disorientation angle of $5^{\circ}$ using the post-processing Chanel 5 software. To characterize the recrystallized grains the criterion $\omega<\omega_{\min }$ was used, $\omega$ being the GOS (Grain Orientation Spread) value of the grain and $\omega_{\min }$ an arbitrary value taken here as $\omega_{\min }=2.5^{\circ}$, which has been seen as a reasonable value to estimate recrystallization fractions. ${ }^{[10,11]}$

After the two steps of the thermo-mechanical treatment (Table 2), tensile specimens were machined along the longitudinal direction (i.e., the rolling direction used for our $75 \%$ cold rolling). The samples were small dog-bone-shaped specimens (total length $L_{0}=43 \mathrm{~mm}$, gauge length $L_{\mathrm{g}}=11.0 \mathrm{~mm}$, width $w_{0}=3.0 \mathrm{~mm}$, thickness $t_{\mathrm{o}}=0.5 \mathrm{~mm}$ ). Tensile tests were made at room temperature on a Deben Microtest MT10331-1kN tensile machine. The crosshead speed in the tensile stage was set to $0.5 \mathrm{~mm} \mathrm{~min}^{-1}=0.0083 \mathrm{~mm} \mathrm{~s}^{-1}$, which corresponds to an initial strain rate of $7.5 \times 10^{-4} \mathrm{~s}^{-1}$.

\section{Results}

An example of microstructure as seen from EBSD map is presented in Figure 1. In this particular case (sample T2), one recognizes that the specimen is not fully recrystallized (Figure 1 shows a small part, i.e., a subset, of the whole EBSD map).

Some of the characteristics of the microstructures are given in Table 3. D_mean is the mean grain size, GOS_mean is the mean value of the GOS of all the grains with an area larger than 3 pixels and Fr_ReX is the fraction of recrystallized grains determined, according to the condition previously described. As one can see in Table 3, samples $R 1$ and $T 1$ correspond to a state, where recrystallization was followed by grain growth. In the other cases, the recrystallization is stopped close to the end of primary recrystallization (samples $R 2$ and $T 2$ ) or even before (samples $R 3, R 4$, and $T 3$ ) leading to much smaller grain size for these two last situations.

The ODFs of the seven samples were calculated using the orientations determined in the EBSD maps. Figure 2 shows for the seven cases the most representative section of the ODF (section $\phi_{1}=0^{\circ}$ ). For the R-type specimens (75\% cold rolling // to the initial $R D$ ) one obtains the "classical" textures. ${ }^{[4,5,7,12]}$ For both the partially recrystallized case and the "end of primary recrystallization" case, the texture resembles much the deformation texture with a maximum at $\left\{\phi_{1}=0^{\circ}, \Phi=40^{\circ}, \phi_{2}=0^{\circ}\right\}$. In the state "recrystallized + grain growth", the typical maximum appears at $\left\{\phi_{1}=0^{\circ}, \Phi=40^{\circ}, \phi_{2}=30^{\circ}\right\}$. In all the three cases, the texture is not very sharp with a maximal value between 7.3 and 8.8 and a significant spread around these ideal orientations. Although rolled in the TD direction, the T-type samples do not show very different ODF's. The main difference is that the maxima are shifted toward smaller values of $\Phi\left(\Phi \approx 25^{\circ}\right.$, i.e., the $c$ axes are much closer to ND). Note, that for the texture calculations we used the Euler angles as defined by Bunge ${ }^{[13]}$ and the crystal coordinate system $\left\{X=\left[\begin{array}{llll}1 & 0 & -1 & 0\end{array}\right], Y=\left[\begin{array}{llll}-1 & 2 & -1 & 0\end{array}\right]\right.$, $Z=[0001]\}$.

After the microstructure and texture characterization, the tensile tests were performed up to the specimen fracture. Figure 3 shows the tensile curves of the seven samples (engineering stress and strain).

The main characteristics of these tests are recapitulated in Table 4.

In Table 4, $\sigma_{e}$ is the yield stress, L_P1 stands for the length (in $\%)$ of the first plateau, which appears sometimes in the beginning of the plastic deformation, $\sigma_{\max }$ is the maximal stress,

Table 2. Deformations (cold rolling $(C R)$ ) and heat treatments applied to generate the seven samples

\begin{tabular}{|c|c|c|c|c|c|}
\hline \multirow[b]{2}{*}{$R 1$} & \multicolumn{2}{|c|}{ Deformation condition } & \multicolumn{2}{|c|}{ Heat treatment } & \multirow{2}{*}{$\begin{array}{c}\text { State of the material } \\
\text { Fully recrystallized (+grain growth) }\end{array}$} \\
\hline & $75 \%$ CR & $/ / R D$ & TT1 & $740^{\circ} \mathrm{C}-2 \mathrm{~h}$ & \\
\hline$R 2$ & $75 \% \mathrm{CR}$ & $/ / R D$ & TT2 & $500^{\circ} \mathrm{C}-1 \mathrm{~h}$ & $\approx$ end of primary recrystallization \\
\hline R3 & $75 \% \mathrm{CR}$ & $/ / R D$ & TT3 & $470^{\circ} \mathrm{C}-2 \mathrm{~h}$ & Partially recrystallized \\
\hline$R 4$ & $75 \%$ CR & $/ / R D$ & TT4 & $500^{\circ} \mathrm{C}-40 \mathrm{mn}$ & Partially recrystallized \\
\hline$T 1$ & $75 \%$ CR & $/ / T D$ & TT1 & $740^{\circ} \mathrm{C}-2 \mathrm{~h}$ & Fully recrystallized (+grain growth) gg) \\
\hline$T 2$ & $75 \% \mathrm{CR}$ & $/ / T D$ & TT2 & $500^{\circ} \mathrm{C}-1 \mathrm{~h}$ & $\approx$ end of primary recrystallization \\
\hline T3 & $75 \% \mathrm{CR}$ & $/ / T D$ & TT3 & $470^{\circ} \mathrm{C}-2 \mathrm{~h}$ & Partially recrystallized \\
\hline
\end{tabular}



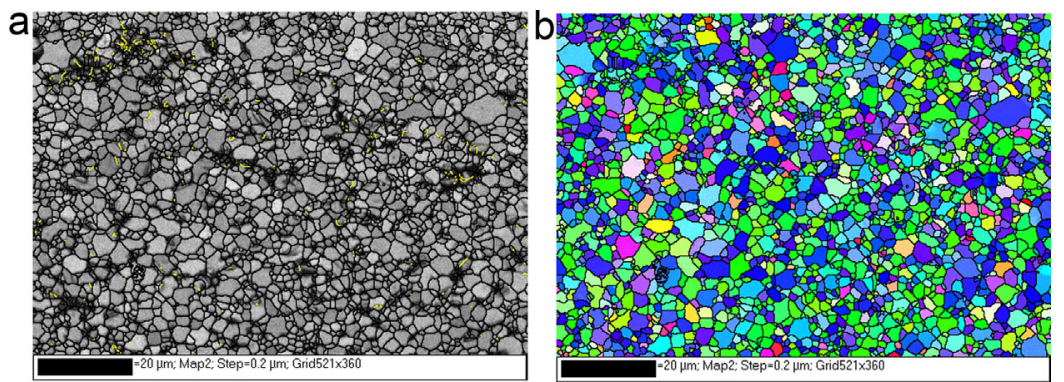

Figure 1. EBSD maps for the specimen T2; (a) BC (Band Contrast) map - grain boundaries over $5^{\circ}$ are in black, whereas boundaries between 3 and $5^{\circ}$ are in yellow (b) IP (Inverse Pole Figure) map for the RD direction - most of the grain are green $(<10-10>/ / \mathrm{RD})$ or blue $(<11-20>/ / R D)$.

$\varepsilon^{*}$ is the corresponding strain (in \%), $\Delta \sigma=\sigma_{\max }-\sigma_{e}$ and $\varepsilon_{r}$ is the strain at break (in \%). L_P2 gives the length of the curve (in \%) between the two points where the stress is equal to $\sigma_{\max }-5 \%$; this quantity intends to reflect the fact that the curves are relatively flat and that the plastic deformation continues in a significant way once the homogeneous deformation is finished (i.e., after $\left.\varepsilon^{*}\right)$. The quantities in Table 4 are estimated to have an uncertainty of $\pm 5 \%$.

\section{Discussion}

\subsection{Yield Stress}

The level of the YS depends first on the activated deformation systems (and on their critical resolved shear stress (crss)). In the present case, some post-mortem SEM observations have shown that there are nearly no twins. The tensile deformation is then due to slip systems. When considering the SF (Schmid Factor) values at the beginning of the deformation, it appears that prismatic, pyramidal $<\mathrm{a}>$ and pyramidal $<\mathrm{c}+\mathrm{a}>$ systems are relatively well oriented in the cases $R 1$ and $T 1$ (see Figure 4). To construct Figure 4, the SF factors are calculated for all the grains of a given specimen and for the several slip system families. Then, for each given SF value, the volume fraction of the grains having a SF greater or equal to this given one is calculated. For example, in the case $R 1,82 \%$ of the grains have a $\mathrm{SF}>0.4$ for prismatic slip and $90 \%$ of the grains have a $\mathrm{SF}>0.4$ for pyramidal

Table 3. Main characteristics deduced from the EBSD maps for the seven analyzed samples

\begin{tabular}{lcccc} 
Sample & Number of grains in the map & D_mean & GOS_mean & Fr_ReX in \% \\
\hline$R 1$ & 4074 & $11.7 \mu \mathrm{m}$ & $0.60^{\circ}$ & $99.6 \%$ \\
$R 2$ & 13185 & $1.8 \mu \mathrm{m}$ & $0.99^{\circ}$ & $91 \%$ \\
$R 4$ & 16928 & $1.7 \mu \mathrm{m}$ & $1.14^{\circ}$ & $79 \%$ \\
$R 3$ & 25781 & $1.2 \mu \mathrm{m}$ & $1.34^{\circ}$ & $62 \%$ \\
$T 1$ & 2599 & $10.9 \mu \mathrm{m}$ & $0.62^{\circ}$ & $99.5 \%$ \\
$T 2$ & 13392 & $1.8 \mu \mathrm{m}$ & $0.67^{\circ}$ & $98 \%$ \\
$T 3$ & 29957 & $1.2 \mu \mathrm{m}$ & $1.13^{\circ}$ & $80 \%$
\end{tabular}

slips, whereas only $10 \%$ of the grains have $\mathrm{SF}>0.4$ for basal slip. The situation is very similar for the other $R$ and $T$ samples.

If one admits that plastic deformation begins with the easiest slip system (the prismatic one), this gives an apparent crss around $140 \mathrm{MPa}$ for these slip systems in the case $R 1$ (the case with the largest mean grain size in our study, assuming a Schmid factor of 0.45 ). This value is in agreement with some data reported in the literature. ${ }^{[14,15]}$

The YS increases significantly, from 315$490 \mathrm{MPa}$ for $R$-type samples and from 300$485 \mathrm{MPa}$ for T-type samples, when the heat treatment is "reduced". The "reduced" heat treatments (TT2, TT3, and TT4 in Table 2) lead to much smaller grains. If one plots the YS versus $D_{\text {mean }}$, the points fit well a Hall-Petch curve (YS $\left.=\sigma_{0}+k / \sqrt{D_{-} \text {mean }}\right)$, as it can be seen in Figure 5. When fitting the Hall-Petch curve with the data (the ones reported here and some others coming from tensile tests not presented in the present study) one obtains for the parameters of the Hall-Petch law $\sigma_{0}=220 \mathrm{MPa}$ and $k=10.0 \mathrm{MPa} \mathrm{mm}{ }^{0.5}$. These values are relatively close to the ones reported in ref.[6] for a similar titanium alloy grade 2 with a little more oxygen $\left(\sigma_{0}=253 \mathrm{MPa}\right.$ and $k=11.3 \mathrm{MPa} \mathrm{mm}^{0.5}$ in ref.[6]).

The increase of the YS is then clearly linked with the reduction of the mean grain size generated by the thermo-mechanical treatment.

One should note that the apparent crss is sometimes described as the sum of several terms: the "intrinsic" crss (lattice friction stress), a Taylor hardening term linked with the dislocation density ${ }^{[16]}$ and an hardening term linked with the grain size. ${ }^{[17,18]}$ Assuming that there is almost no hardening contribution due to the dislocation density which is low when starting the extension and that the other hardening term is $\mathrm{k} /$ $D_{\text {mean }} 0.5$, one obtains a value of $95 \mathrm{MPa}$ for the "intrinsic" crss (due to lattice friction) for prismatic slip.

\subsection{Anisotropy}

Titanium is known to exhibit a significant plastic anisotropy. It is then important, in order to discuss the YS and to estimate the ductility, to consider the plastic deformation in the transverse direction. For the four specimens $R 1-R 4$, supplementary stressstrain curves were made with the transverse direction as the elongation direction. The engineering stress strain curves are shown in Figure 6 (the notation $R T j$ with $j=1,2$, 3, or 4 means then sample $R j$ was extended in the transverse direction).

In the four cases, the YS is higher compared to the extension along $R D$ (with an increase of about $100 \mathrm{MPa}$ ). This is of course linked with the textures. For the well recrystallized case (specimen R1), there is still a small hardening. The homogeneous deformation, $\varepsilon^{*}$, as well as $\varepsilon_{p}$ the deformation at break, are nevertheless somewhat decreased compared with the case of elongation along $R D$. In the three other cases, the homogeneous deformation is quite limited and some softening appears. 

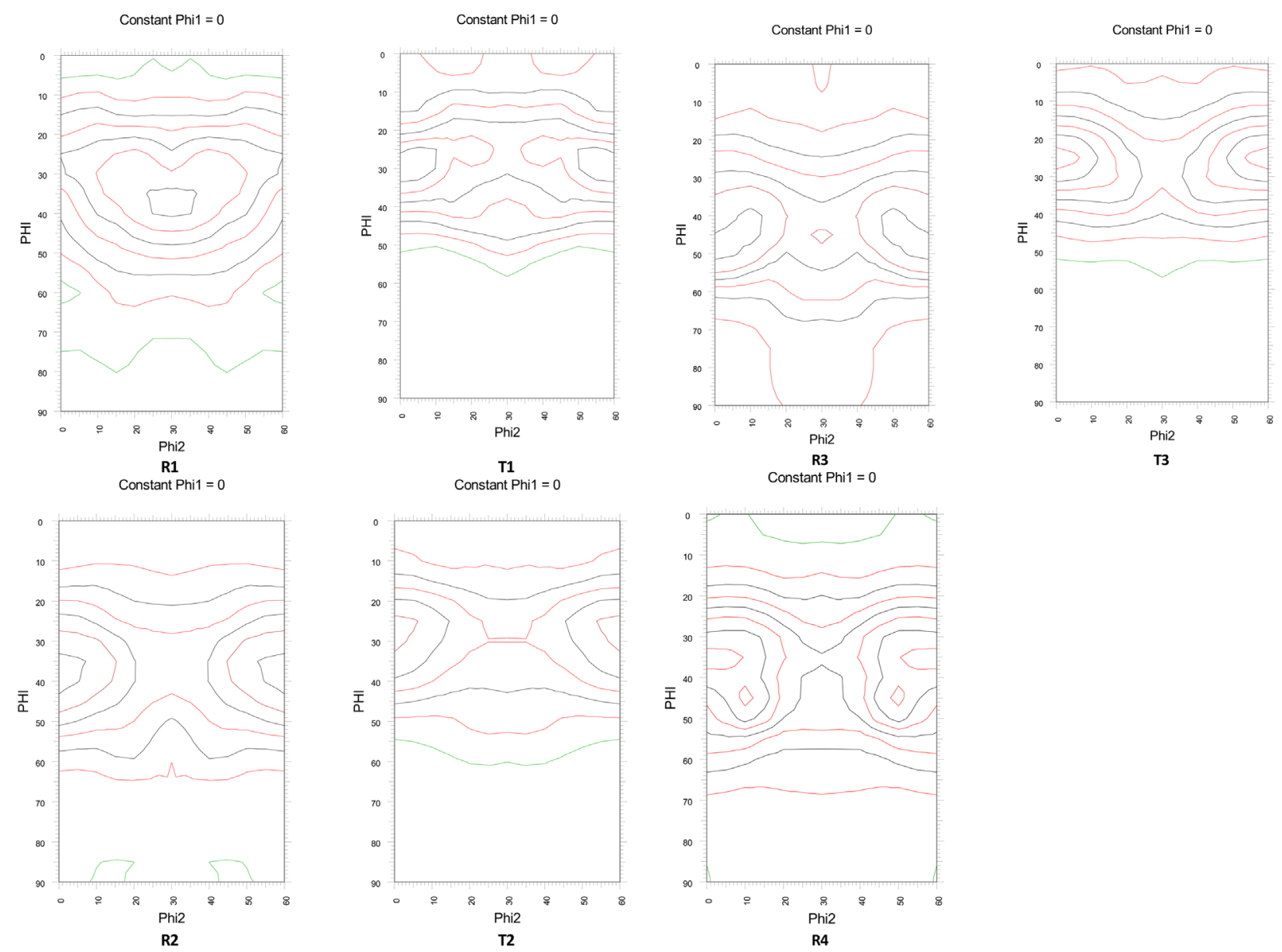

Figure 2. Section $\phi_{1}=0^{\circ}$ of the ODF's of the seven specimens; levels: 1. (green), 2. (red), 3. (black), 4. (red), 5. (black), 6. (red), 7. (black), 8. (red), 9. (black).

The increase of the YS is clearly linked with the fact that the prismatic systems are not so well oriented for the elongation along $T D$ and that a higher amount of the deformation is due to pyramidal and basal slip (see Figure 7). For example, in the case of the $R 1$ specimen, there are only $38 \%$ of the grains with a Schmid factor larger than 0.4 for prismatic systems (to be compared to $82 \%$ for $R D$ elongation). For the basal and pyramidal $<\mathrm{c}+\mathrm{a}>$ systems one obtains 46 and $70 \%$, respectively, always for a Schmid factor larger than 0.4 , (to be compared to 10 and $96 \%$ for $R D$ elongation). The situation is rather similar for the other $R$ specimens because their textures are not very different from that of the $R 1$ specimen. The fact that the YS is essentially controlled by prismatic slips was also underlined in several papers. ${ }^{[15,19,20]}$

The very rapid softening observed for the specimens RT3 and RT4 is likely correlated with the strain path change, meaning a change from rolling (plane strain) to the tensile testing along $T D$. Indeed the "reduced" heat treatment made after the cold rolling does not completely "erase" the dislocation structure generated during the cold rolling for a fraction of the material (not recrystallized). For a given constant strain path, the stress states of individual grains correspond to a given vertex on the yield surface because multiple slip is needed for large strains. When the strain path is changed, another vertex is needed to be activated on the yield surface. Note that the vertices are situated farther from the origin, so when the stress state is moving along a facet of the yield surface, smaller stress states is needed for plasticity, which explains the reduction in the stress level.
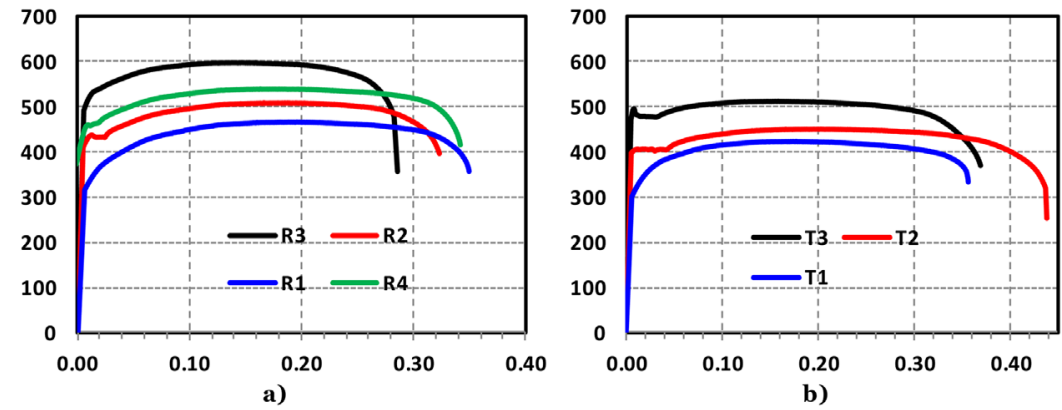

Figure 3. Stress (MPa)-strain curves (engineering) for the samples (a) R1 (blue), R2 (red), R3 (black), R4 (green) and (b) T1 (blue), T2 (red), T3 (black). 
Table 4. Main characteristics for the seven stensile tests

\begin{tabular}{lccccccc} 
sample & $\sigma_{e}$ & L_P1 & $\sigma_{\max }$ & $\varepsilon^{*}$ & $\Delta \sigma$ & L_P2 & $\varepsilon_{r}$ \\
\hline & {$[\mathrm{MPa}]$} & {$[\%]$} & {$[\mathrm{MPa}]$} & $\%$ & {$[\mathrm{MPa}]$} & {$[\%]$} & {$[\%]$} \\
$R 1$ & 315 & - & 466 & 19.5 & 151 & 22.5 & 35.0 \\
$R 2$ & 420 & 1.9 & 510 & 19.6 & 90 & 21.4 & 32.4 \\
$R 4$ & 439 & 1.0 & 538 & 17.3 & 99 & 25.0 & 33.7 \\
$R 3$ & 490 & - & 600 & 14.6 & 110 & 20.4 & 27.6 \\
$T 1$ & 300 & - & 425 & 19.0 & 125 & 24.0 & 35.0 \\
$T 2$ & 400 & 3.7 & 450 & 19.5 & 50 & 29.4 & 43.0 \\
$T 3$ & 485 & 2.1 & 512 & 17.0 & 27 & 26.2 & 36.5
\end{tabular}

\subsection{Hardening and Ductility}

In all cases ( $R 1$ to $R 4, T 1$ to $T 3$ ), after a short elongation range where the stress increases, there is a large deformation range with a nearly flat curve. The homogeneous deformation, as deduced from the Considère criterion, ranges between 19.5 and $14.6 \%$ ( $R$ samples) and between 19.0 and $17.0 \%$ ( $T$ samples). Once plastic deformation has started, preferentially on the easiest slip system, incompatibilities develop and harder slip systems could be activated because the local stress states deviate significantly from the macroscopic stress state, especially in the vicinity of grain boundaries.

Hardening, in the classical view, is a balance between hardening due to the increase of the dislocation density during plastic deformation and softening due, for example, to dislocation absorption by grain boundaries. ${ }^{[21]}$ It appears here that an equilibrium between these two mechanisms is rapidly reached, allowing a good ductility.

The global trend is a decrease of the amplitude of the hardening, as defined by $\Delta \sigma=\sigma_{\max }-\sigma_{e}$ in Table 4 , when the heat treatment is "reduced" giving rise to smaller grain size. The ratio grain boundary area over volume increases significantly, when the grain size is reduced. The capability of absorption of dislocations is strongly enhanced and the hardening amplitude is then reduced.

The decrease of the recrystallized volume fraction gradually induces a loss in ductility. ${ }^{[8]}$ Once the maximal engineering stress is reached (Considère criterion), this balance allows plastic
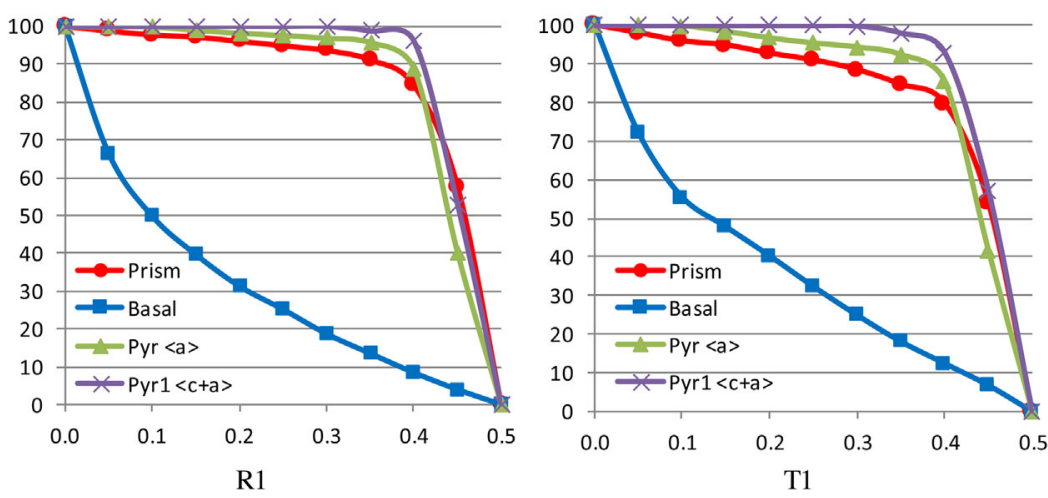

Figure 4. Volume fraction of the grains (cumulative) as a function of Schmid factor values for the cases R 1 and $\mathrm{T} 1$ (volume fraction in \% on the vertical axis, SF values on the horizontal axis).

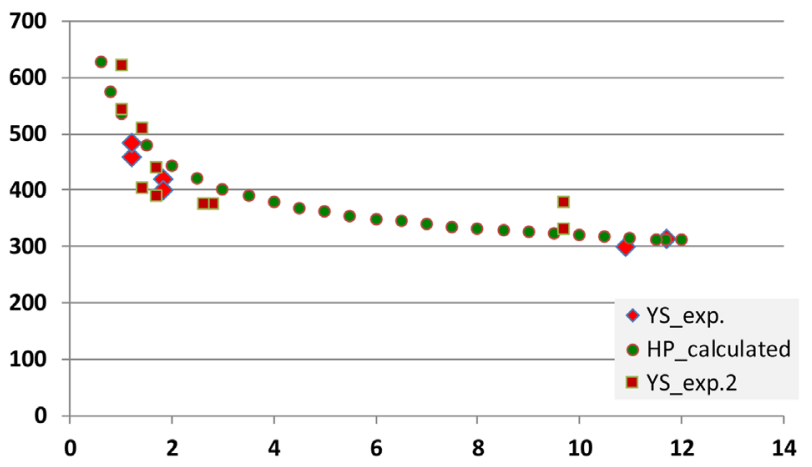

Figure 5. Yield Stress (MPa) versus the mean grain size D_mean (in $\mu \mathrm{m}$ ) (losange: exp. values for the seven samples; squares: other exp. values; circles: calculated values according to the Hall-Petch relation with $\sigma_{0}=220 \mathrm{MPa}$ and $k=10.0 \mathrm{MPa} \mathrm{mm}^{0.5}$ ).

deformation to continue up to a high elongation value $\left(\varepsilon_{r}\right.$ the elongation at break, ranges between 35 and $28 \%$ for $R$ samples and between 43 and $36 \%$ for $T$ samples). A high strain rate sensitivity is known to promote such behavior. ${ }^{[22]}$

Samples strained along $R D$ display much higher workhardening than those strained along $T D$, in accordance with previous observations on well-recrystallized cp Ti specimens. ${ }^{[15,19]}$ Such difference was recently reproduced from self-consistent simulations by assuming a higher dislocation multiplication rate for prismatic systems, which leads to a higher dislocation density in $R D$-samples compared to $T D$-ones due to a stronger contribution of prismatic slip and finally to a higher work-hardening rate. ${ }^{[15]}$

\section{Conclusions}

The present study shows that it is possible to increase quite significantly the YS, more than $50 \%$ for the considered cp titanium sheets, by optimizing the heat treatment at the end of the elaboration stage. The main reason of this increase is the reduction in grain size, the YS following a Hall-Petch law as it was clearly evidenced. This induces a very limited decrease of the ductility, when the volume fraction of the recrystallized grains remains high (more than 80\%). This stands for extension along $R D$. For extension along $T D$, the homogeneous deformation decreases strongly when the material contains a fraction of non-recrystallized grains. A good compromise for high YS and satisfactory ductility is then the metallurgical state close to the end of primary recrystallization, which insures a relatively small grain size, all of them being recrystallized. Such heat treatment optimization can be used to design conditions allowing mass saving in the applications.

\section{Acknowledgements}

The authors thank Dr. Laurent Peltier for performing various heat treatments, Mr Yvon Millet from the company Timet for providing cp Ti sheets, Dr. Cai Chen for technical help and Dr. M. R. Barnett for fructuous 


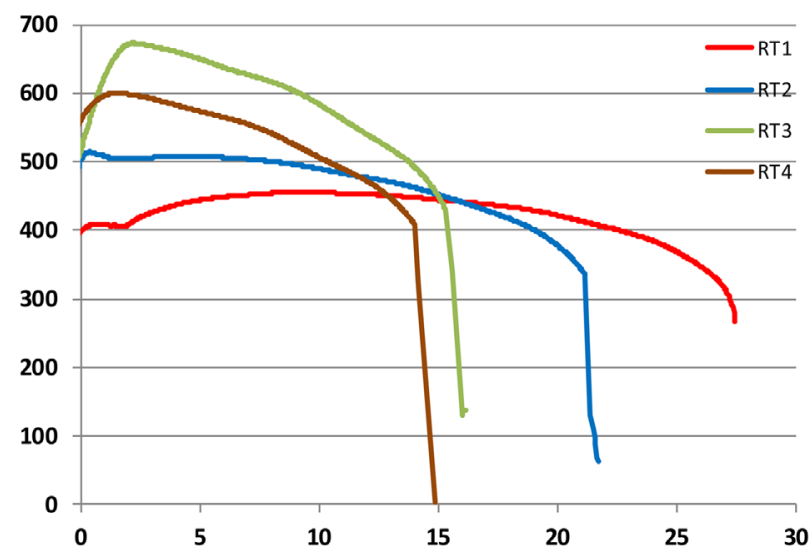

Figure 6. Stress-strain curves (engineering) for the four specimens R1R4 extended along TD (strain is here in \%).

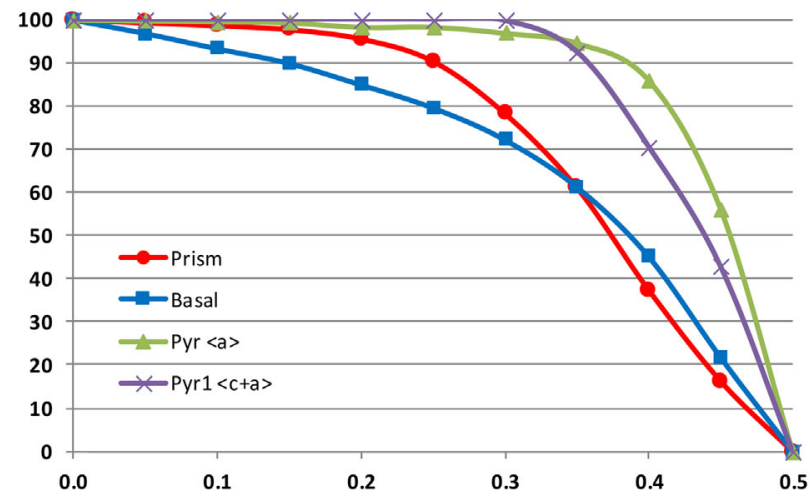

Figure 7. Volume fraction of the grains (cumulative) as a function of Schmid factor values for the specimen R1 elongated along TD (volume fraction in \% on the vertical axis, SF values on the horizontal axis).

discussions. This work was supported by the French State through the program "Investment in the future" operated by the National Research Agency (ANR) and referenced by ANR-11-LABX-0008-01 (LabEx DAMAS).

\section{Conflict of Interest}

The authors declare no conflict of interest.

\section{Keywords}

grain size; hardening; heat treatment; mechanical properties; texture; titanium

Received: March 16, 2017

Revised: May 16, 2017

Published online: June 19, 2017

[1] M. Ashby, Materials Selection in Mechanical Design 3rd edn, Butterworth-Heinemann, Burlington, Massachusetts 1999.

[2] N. Bayona-Carrillo, N. Bozzolo, J. J. Fundenberger, B. Thomas, P. Camelin, E. Lenarduzzi, F. Wagner, Adv. Eng. Mater. 2011, 13, 383.

[3] K. L. Murty, I. Charit, Prog. Nucl. Energy 2006, 48, 325.

[4] F. Wagner, N. Bozzolo, O. Van Landuyt, T. Grosdidier, Acta Mater. 2002, 50, 1245.

[5] A. K. Singh, R. A. Schwarzer, Trans. Indian Inst. Met. 2008, 61, 371.

[6] A. Ghaderi, M. R. Barnett, Acta Mater. 2011, 59, 7824.

[7] Y. N. Wang, J. C. Huang, Mater. Chem. Phys. 2003, 81, 11.

[8] X. Lei, L. Dong, Z. Zhang, Y. Liu, Y. Hao, R. Yang, L.-C. Zhang, Metals 2017, 7, 1 doi: 10.3390/met7040131

[9] Y. B. Chun, S. L. Semiatin, S. K. Hwang, Acta Mater. 2006, 54, 3673.

[10] P. Gerber, J. Tarasiuk, R. Chiron, B. Bacroix, Arch. Met. Mater. 2005, 50, 747.

[11] A. Ayad, N. Allain-Bonasso, N. Rouag, F. Wagner, Mater. Sci. Forum 2012, 702-703, 269.

[12] N. Benmhenni, S. Bouvier, R. Brenner, T. Chauveau, B. Bacroix, Mater. Sci. Eng. A 2013, A573, 222.

[13] H. J. Bunge, Texture Analysis in Material Science Butterworths, London 1982.

[14] B. Barkia, V. Doquet, J. P. Couzinié, I. Guillot, E. Héripré, Mater. Sci. Eng. A 2015, A636, 91.

[15] K. E. K. Amouzou, T. Richeton, A. Roth, M. A. Lebyodkin, T. A. Lebedkina, Int. J. Plast. 2015, 80, 222.

[16] P. Franciosi, M. Berveiller, A. Zaoui, Acta Metall. 1980, 28, 273.

[17] H. J. Bunge, F. Wagner, P. I. Welch et P. Van-Houtte, J. Phys. Lett. 1985, 46, L1109.

[18] N. Nicaise, S. Berbenni, F. Wagner, M. Berveiller, X. Lemoine, Int. J. Plast. 2011, 27, 232.

[19] A. Roth, M. A. Lebyodkin, T. A. Lebedkina, J.-S. Lecomte, T. Richeton, K. E. K. Amouzou, Mater. Sci. Eng. A 2014, A596, 236.

[20] J. W. Won, K.-T Park, S.-G Hong, C. Lee, Mater. Sci. Eng. A 2015, A637, 215.

[21] U. F. Kocks, H. Mecking, Prog. Mater. Sci. 2003, 48, 171.

[22] G. Gottstein, Physical Foundations of Materials Science, SpringerVerlag, Berlin, Heidelberg 2004. 